\title{
Sistem Informasi Pengelolaan Zakat Profesi pada Badan Amil Zakat Nasional (BAZNAS) Kabupaten Bogor
}

\author{
Fintri Indriyani $^{\# 1}$, Abdullah Guntur Wahyu ${ }^{* 2}$ \\ "Sistem Informasi Akuntansi, Universitas Bina Sarana Informatika, \\ Jl. Kamal Raya No.18, Ring Road Barat, Cengkareng, Jakarta Barat, Indonesia \\ ${ }^{1}$ fintri.fni@bsi.ac.id \\ "Sistem Informasi, STMIK, Nusa Mandiri, \\ Jl. Damai No. 8, Warung Jati Barat, Jakarta Selatan, Indonesia \\ ª.guntur.w@gmail.com
}

\begin{abstract}
Abstrak-Zakat sebagaimana kebutuhan pokok bagi umat islam yang harus dipenuhi agar harta yang dimiliki bersih dan berkah. Zakat profesi merupakan salah satu dari jenis zakat yang wajib dikeluarkan oleh pegawai apabila telah mencapai nishabnya. Badan Amil Zakat Nasional Kab. Bogor adalah lembaga yang mengelola zakat bagi masyarakat Bogor yang saat ini masih menerima secara langsung dana dari para muzakki dan petugas masih melakukan pencatatan secara manual sehingga data yang ada menumpuk dan kurang terorganisir dengan baik, selain itu para muzaki harus menyempatkan waktunya untuk melakukan kewajibannya berzakat. Sistem Informasi pengelolaan zakat profesi ini dibuat dengan metode waterfall dan pengujian web menggunakan metode blackbox testing. Pembuatan system informasi ini bertujuan agar memudahkan muzaki dan pengelola serta meningkatkan kepercayaan mereka terhadap BAZNAS. Dengan penerapan system informasi ini muzaki menjadi mudah untuk menyalurkan zakat profesinya, dan menambah kepercayaan karena adanya transparansi dari laporan penyaluran zakat.
\end{abstract}

Kata kunci- Sistem Informasi, Pembayaran Zakat, Website, Zakat Profesi, BAZNAS.

\section{PENDAHULUAN}

\section{A. Latar Belakang}

Peningkatan kualitas dibidang sosial melalui program pembayaran zakat dipandang sebagai salah satu upaya dalam mengurangi angka kemiskinan [1]. Apabila setiap muzakki menyadari kewajibannya untuk membayar zakat dan badan pengelola zakat dapat menyalurkan secara transparan maka esensi zakat akan terasa manfaatnya bagi masyarakat luas. Salah satu komponen Zakat pada BAZNAS Kabupaten Bogor di peroleh dari zakat profesi para Pegawai Negeri Sipil (PNS) yang masih belum efisien dalam pembayaran dan pendataannya, karena dilakukan secara penerimaan langsung atau masih manual dengan cara datang ke kantor BAZNAS pada jam kerja. Untuk dapat menghemat waktu dan memberikan kemudahan, maka sistem dengan melakukan pembayaran secara online melalui website ini dibuat agar muzaki tidak harus datang ke kantor BAZNAS Kabupaten Bogor tetapi bisa melakukan pembayaran yang efisien dan menghemat waktu selain itu pelaporan zakat bisa dilakukan secara lebih transparan. Mengapa transparansi menjadi hal penting, menurut [2] diantara hal-hal yang mempengaruhi muza'ki memilih tempat membayar zakat adalah kemudahan, transparansi, profesionalitas dan sosialisasi dari organisasi penerima zakat.

\section{B. Identifikasi Permasalahan}

Berdasarkan Latar Belakang Masalah di atas, maka dapat diidentifikasi masalah tersebut adalah :

1. Pembayaran zakat masih harus datang ke kantor BAZNAS Kabupaten Bogor sehingga mengganggu aktifitas kerja.

2. Sistem informasi penyaluran Zakat di BAZNAS Kabupaten Bogor belum dapat dilihat secara luas karena belum adanya website sendiri sehingga jarang sekali masyarakat mengetahui kegiatan BAZNAS Kabupaten Bogor. 
3. Sistem informasi laporan pemasukan dan pengeluaran dana zakat lebih cepat terlihat secara luas dengan adanya update website.

\section{LANDASAN TEORI DAN STUDI PUSTAKA}

\section{A. Metode Pengembangan Sistem}

Dalam pengembangan system informasi pengelolaan zakat ini digunakan metode waterfall, Menurut [3] Waterfall adalah alur hidup klasik dimana pendekatan alur hidup secara terurut dengan fase analisa, desain, pengkodean, pengujian dan pendukung. Adapun tahapan yang dibuat dalam system ini adalah:

a. Analisa kebutuhan system

Dilakukan dengan pengamatan lapangan dan wawancara untuk mendapatkan informasi mengenai proses bisnis pengelolaan zakat profesi mulai dari penerimaan zakat hingga pembuatan laporan.

b. Desain

Desain database menggunakan ERD (Entity

Relationship Diagram) dan desain sistem dengan UML diantaranya usecase diagram, activity diagram.

c. Pengkodean

Pengkodean menggunakan php sebagai bahasa pemrograman dan mysql untuk databasenya.

d. Pengujian

Pengujian menggunakan blackbox testing untuk menguji fungsi-fungsi dalam program.

e. Pendukung

Selain menggunakan xampp, digunakan photoshop untuk mendesain tampilan agar lebih menarik.

\section{B. $U M L$}

Menurut [4] "UML singkatan dari Unified Modelling Language yang berarti bahasa pemodelan standar". Blok pembangunan utama $U M L$ adalah diagram. $U M L$ merupakan alat komunikasi yang konsisten dalam mensuport para pengembang sistem saat ini.

\section{Black Box Testing}

Menurut [5] "black box testing adalah metode dimana penguji atau tester hanya mengetahui apa yang harus dilakukan suatu software. Penguji tidak mengetahui bagaimana software tersebut beroperasi".

\section{Zakat}

Menurut Undang-Undang No. 38/1999 pasal 1 ayat 2 disebutkan, yang dimaksud dengan zakat adalah harta yang wajib disisihkan oleh seorang muslim atau badan yang dimiliki oleh orang muslim sesuai dengan ketentuan agama untuk di berikan kepada yang berhak menerimanya.

Menurut [6] zakat profesi adalah kewajiban mengeluarkan zakat dari pengehasilan yang didasarkan pada sebuah profesi. Kadar zakat profesi diserupakan dengan zakat uang/emas/perak. Karena gaji, upah, honorium dan lainya umumnya diterima dalam bentuk uang. Karena itu, kadar zakat profesi seorang pegawai adalah 2,5\%.

\section{E. Penelitian Terkait}

Tingkat kepercayaan dan kurangnya pengetahuan mekanisme serta keberadaan UPZ (Unit Pengelola Zakat) merupakan faktor yang mempengaruhi pengumpulan dana zakat di Indonesia sehingga diperlukan system informasi yang dapat mengatur manajemen pengelolaan zakat.[7]

Perhitungan zakat secara manual tidaklah mudah untuk itu dibangunlah aplikasi guna menghitung jenis dan besar zakat yang harus dikeluarkan. [8]

Proses perhitungan, penyaluran dan pengawasan zakat di Kecamatan Lubuk masih menggunakan system manual sehingga memungkinkan terjadi manipulasi dan menyulitkan petugas dalam membuat laporan maka dibuatlah aplikasi yang terintegrasi dengan database sehingga pengelolaan datanya lebih terstuktur dan menghasilkan laporan yang relevan. [9]

\section{F. Tinjauan Perusahaan}

Lembaga BAZNAS adalah lembaga yang bergerak dibidang sosial, Undang-Undang Pengelolaan Zakat (UU No 38 Tahun 1999) lahir di masa Presiden RI Ke-3 B.J. Habibie dan Menteri Agama H.A. Malik Fadjar. Undang-Undang Pengelolaan Zakat tahun 1999 diubah dengan UndangUndang No 23 Tahun 2011 dan diterbitkan Peraturan Pemerintah No 14 Tahun 2014. Pemerintah di masa Presiden Susilo Bambang Yudhoyono menerbitkan Instruksi Presiden No 3 Tahun 2014 tentang Optimalisasi Pengumpulan Zakat di Kementerian/Lembaga, Pemerintah Daerah, BUMN dan BUMD Melalui BAZNAS.

\section{G. Struktur Organisasi dan Fungsi}

Setiap Institusi besar atau Institusi kecil harus memiliki suatu struktur organisasi, dengan adanya struktur organisasi dapat membantu perusahaan untuk mencapai suatu tujuan yang telah ditetapkan. Struktur organisasi sangat bermanfaat bagi seluruh karyawan untuk mengetahui tugas, wewenang dan tanggung jawab yang diberikan oleh perusahaan. Berikut adalah struktur organisasi BAZNAS Kabupaten Bogor:

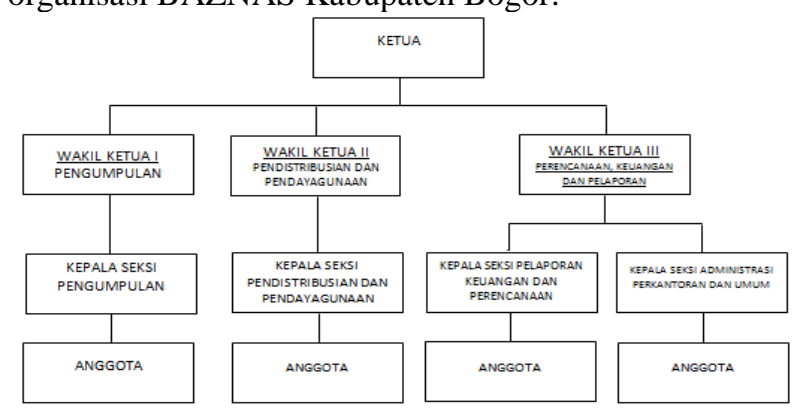

Sumber : BAZNAS Kabupaten Bogor

Gambar 1. Struktur Organisasi BAZNAS Kabupaten Bogor 


\section{H. Proses Bisnis Sistem}

BAZNAS Kabupaten Bogor adalah lembaga bergerak dalam bidang sosial, dalam kegiatan prosesnya di awali ketika muzaki datang ke kantor untuk pembayaran zakat. Kemudian diterima oleh bagian anggota pengumpulan untuk menerima zakat kemudian dibuatkan kuitansi sebagai bukti sudah melakukan pembayaran zakat dan untuk setiap bulanya anggota membuat laporan keuangan.

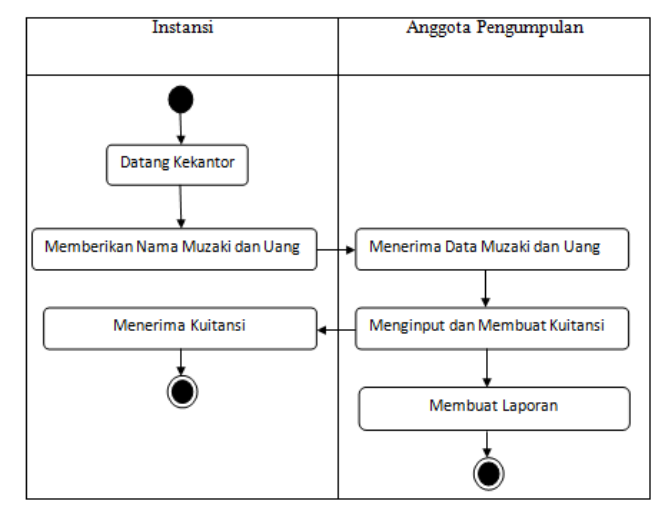

Sumber: BAZNAS Kabupaten Bogor Gambar 2. Activity Diagram Prosedur Pembayaran Zakat Profesi

\section{PEMBAHASAN}

\section{A. Tahapan Penelitian}

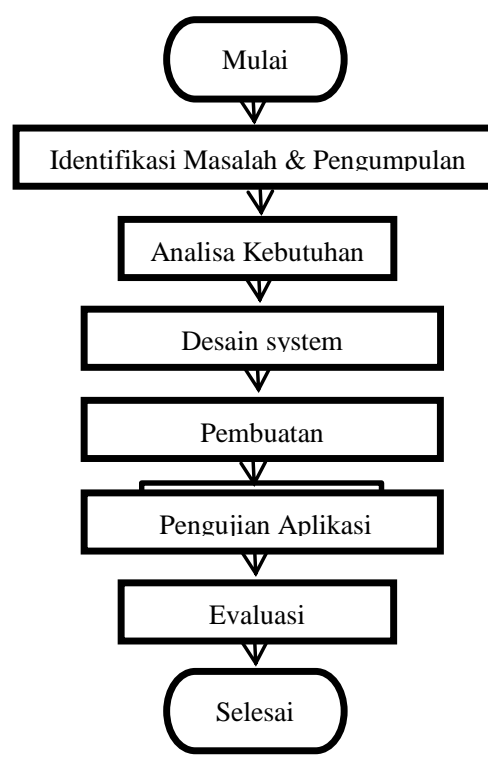

Gambar 3. Tahapan Penelitian

\section{B. Tahapan Analisis}

Pada sistem BAZNAS Kabupaten Bogor begitu banyak Instansi yang ingin mendapatkan informasi lebih tentang pembayaran zakat profesi atau infak sehingga mengharuskan para Instansi untuk datang langsung ke kantor BAZNAS Kabupaten Bogor. Oleh sebab itu muncul ide untuk membuat sebuah halaman web yang akan memudahkan para Instansi untuk memperoleh informasi tentang pembayaran zakat profesi atau infak dalam melakukan transaksi secara online. Berikut ini spesifikasi kebutuhan (system requirement) pada BAZNAS Kabupaten Bogor yaitu:

Halaman User:

A1. User dapat melakukan registrasi dan login.

A2. User melakukan pembayaran dan menerima bukti pembayaran.

A3. User dapat melihat laporan keuangan.

Halaman Admin :

A1. Admin mengelola data user.

A2. Admin mengelola data pendaftaran user.

A3.Admin mengelola data pembayaran zakat profesi dan infak. A4.Admin mengelola data penyaluran zakat profesi dan infak A5.Admin mengelola isi website, kegiatan yang di lakukan BAZNAS Kabupaten Bogor, pembayaran, penyaluran dan laporan.

\section{Desain Sistem}

\section{Use Case Diagram Halaman User}

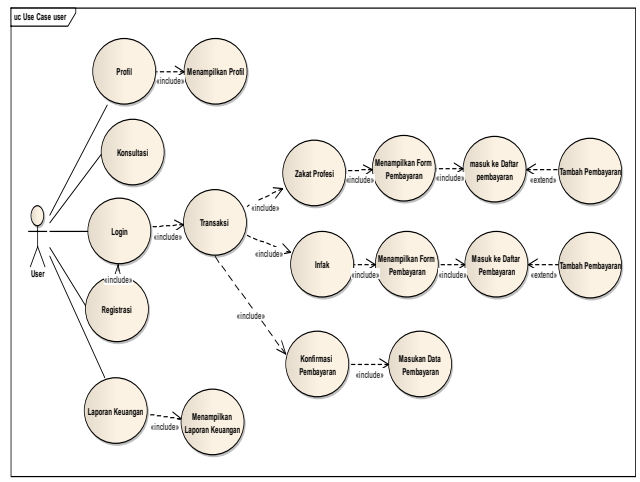

Gambar 4. Use Case Diagram Halaman User

2. Use Case Diagram Halaman Admin

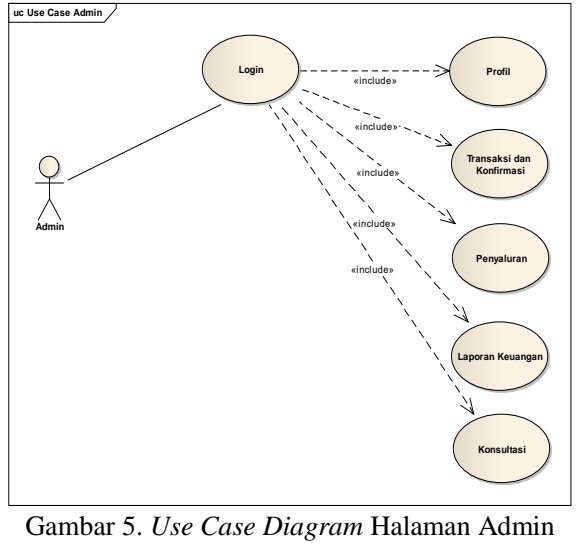




\section{Entity Relationship Diagram}

Berikut adalah bentuk ERD dari perancangan sistem yang dibuat :

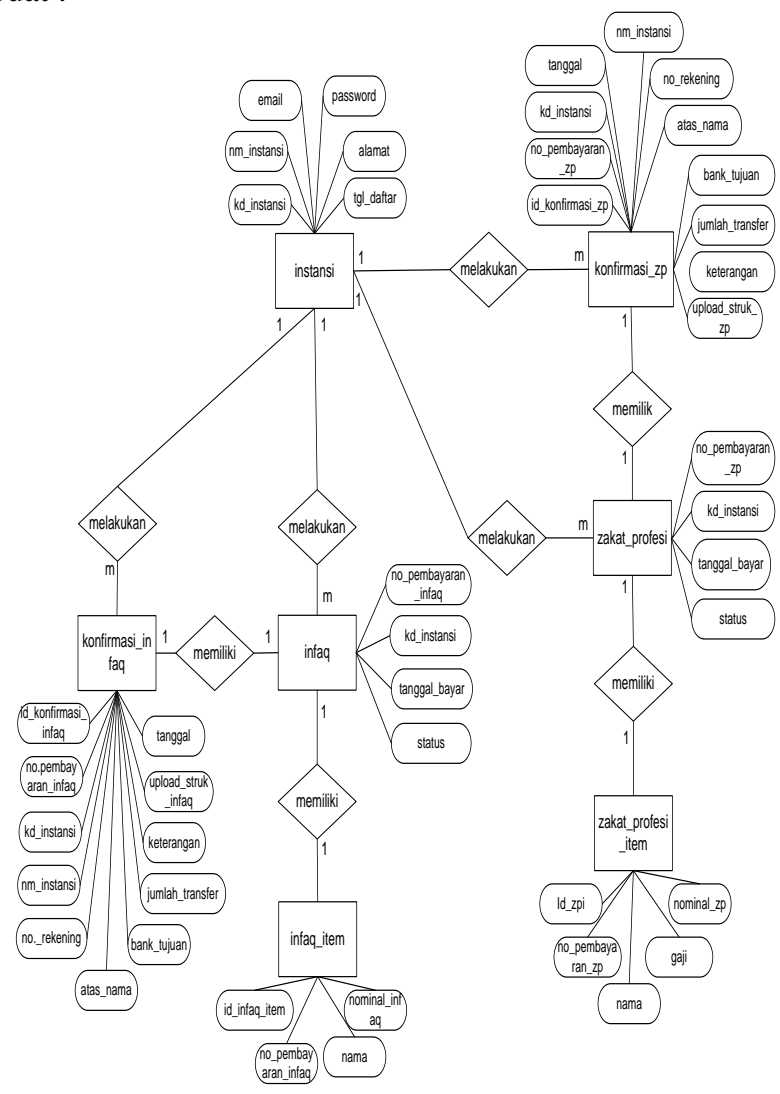

Gambar 6. Entity Relationship Diagram BAZNAS Kabupaten Bogor

\section{Rancangan Antar Muka}

Berikut ini adalah tampilan antarmuka dari web:

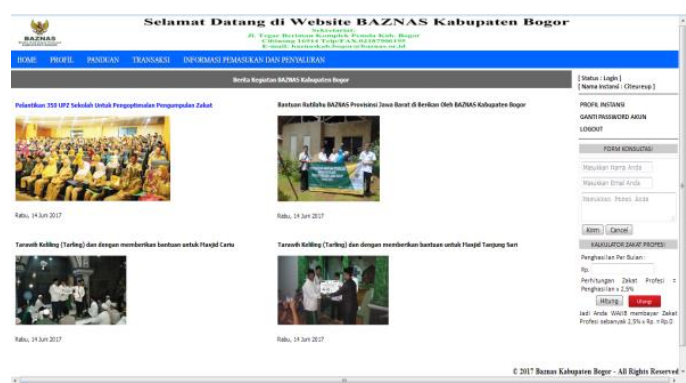

Gambar 7. Tampilan Halaman User

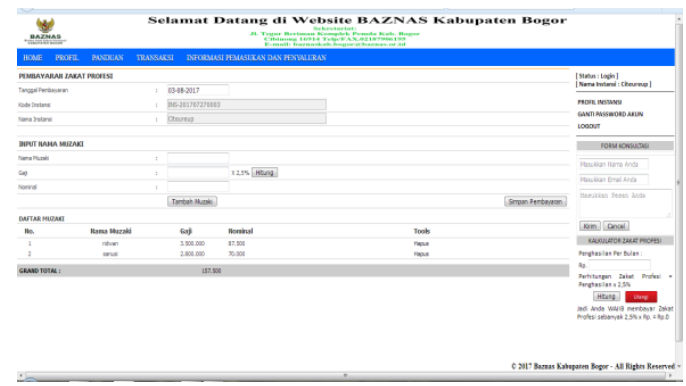

Gambar 8. Tampilan Pembayaran Zakat

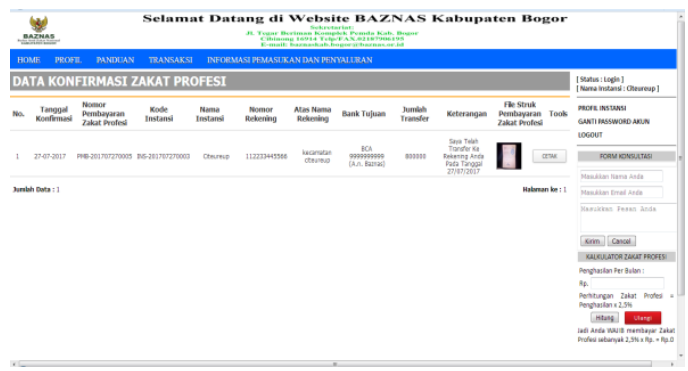

Gambar 9. Tampilan Konfirmasi Pembayaran Zakat

\section{E. Pengujian Black box Testing}

Tabel 1. Black Box Testing Tampilan Pembayaran Zakat

\begin{tabular}{|c|c|c|c|c|}
\hline $\begin{array}{l}\mathrm{N} \\
\mathrm{o}\end{array}$ & $\begin{array}{l}\text { Skenario } \\
\text { Pengujian }\end{array}$ & Test Case & $\begin{array}{l}\text { Hasil yang } \\
\text { diharapkan }\end{array}$ & $\begin{array}{c}\text { Kesimpul } \\
\text { an }\end{array}$ \\
\hline 1 & $\begin{array}{l}\text { Form } \\
\text { pembayaran } \\
\text { zakat profesi } \\
\text { tidak diisi } \\
\text { kemudian } \\
\text { klik Simpan } \\
\text { Pembayaran }\end{array}$ & $\begin{array}{l}\text { Nama Muzaki } \\
=(\text { kosong }) \\
\text { Nominal }= \\
\text { (kosong) }\end{array}$ & $\begin{array}{l}\text { Sistem akan } \\
\text { menolak dan } \\
\text { menampilkan" } \\
\text { DAFTAR } \\
\text { NAMA } \\
\text { MUZAKI } \\
\text { MASIH } \\
\text { KOSONG } \\
\text { belum ada nama } \\
\text { yang } \\
\text { dimasukan, } \\
\text { minimal 1 } \\
\text { nama” } \\
\text { Pada diatas } \\
\text { Form } \\
\text { Pembayaran } \\
\text { zakat profesi }\end{array}$ & Valid \\
\hline 2 & $\begin{array}{l}\text { Memilih } \\
\text { konfirmasi } \\
\text { pemabayaran } \\
\text { tanpa adanya } \\
\text { transaksi } \\
\text { melalui } \\
\text { pemabayaran } \\
\text { zakat profesi }\end{array}$ & Kosong & $\begin{array}{l}\text { Sistem akan } \\
\text { menolak dan } \\
\text { menampilkan" } \\
\text { Anda Tidak } \\
\text { Memiliki } \\
\text { Pemabayaran } \\
\text { Zakat Profesi” } \\
\text { Pada halaman } \\
\text { Konfirmasi } \\
\text { pembayaran }\end{array}$ & Valid \\
\hline
\end{tabular}




\begin{tabular}{|c|c|c|c|c|}
\hline 3 & $\begin{array}{l}\text { Memilih } \\
\text { konfirmasi } \\
\text { pemabayaran } \\
\text { setelah } \\
\text { melakukan } \\
\text { transaksi } \\
\text { pemabayaran } \\
\text { zakat profesi } \\
\text { tetapi tidak } \\
\text { mengisi form } \\
\text { konfirmasi }\end{array}$ & $\begin{array}{l}\text { Atas nama } \\
\text { kosong = } \\
\text { (kosong) } \\
\text { Nomor } \\
\text { rekening = } \\
\text { (kosong) } \\
\text { Keterangan } \\
\text { (kosong) }\end{array}$ & $\begin{array}{l}\text { Sistem akan } \\
\text { menolak dan } \\
\text { menampilkan" } \\
\text { 1. Data nomor } \\
\text { rekening tidak } \\
\text { valid, isi dengan } \\
\text { benar dan } \\
\text { gunakan angka } \\
\text { 2. Data atas } \\
\text { nama rekening } \\
\text { tidak valid, isi } \\
\text { dengan benar } \\
\text { dan gunakan } \\
\text { huruf } \\
\text { 3. Data } \\
\text { Keterangan } \\
\text { masih kosong" } \\
\text { pada diatas } \\
\text { form konfirmasi }\end{array}$ & Valid \\
\hline 4 & $\begin{array}{l}\text { Memilih } \\
\text { konfirmasi } \\
\text { pemabayaran } \\
\text { setelah } \\
\text { melakukan } \\
\text { transaksi } \\
\text { pemabayaran } \\
\text { zakat profesi } \\
\text { tetapi tidak } \\
\text { lengkap } \\
\text { mengisi form } \\
\text { konfirmasi } \\
\end{array}$ & $\begin{array}{l}\text { Atas nama } \\
\text { kosong }=(\text { isi) } \\
\text { Nomor } \\
\text { rekening = } \\
\text { (kosong) } \\
\text { Keterangan } \\
\text { (kosong) }\end{array}$ & $\begin{array}{l}\text { 1. Data nomor } \\
\text { rekening tidak } \\
\text { valid, isi dengan } \\
\text { benar dan } \\
\text { gunakan angka } \\
\text { 2. Data } \\
\text { Keterangan } \\
\text { masih kosong" } \\
\text { pada diatas } \\
\text { form konfirmasi }\end{array}$ & Valid \\
\hline 5 & $\begin{array}{l}\text { Memilih } \\
\text { konfirmasi } \\
\text { pemabayaran } \\
\text { setelah } \\
\text { melakukan } \\
\text { transaksi } \\
\text { pemabayaran } \\
\text { zakat profesi } \\
\text { tetapi tidak } \\
\text { lengkap } \\
\text { mengisi form } \\
\text { konfirmasi }\end{array}$ & $\begin{array}{l}\text { Atas nama } \\
\text { kosong = } \\
\text { (kosong) } \\
\text { Nomor } \\
\text { rekening = } \\
\text { (isi) } \\
\text { Keterangan } \\
\text { (kosong }\end{array}$ & $\begin{array}{l}\text { 1. Data atas } \\
\text { nama rekening } \\
\text { tidak valid, isi } \\
\text { dengan benar } \\
\text { dan gunakan } \\
\text { angka } \\
\text { 2. Data } \\
\text { Keterangan } \\
\text { masih kosong" } \\
\text { pada diatas } \\
\text { form konfirmasi }\end{array}$ & Valid \\
\hline
\end{tabular}

\section{KESIMPULAN}

Berdasarkan uraian penjelasan dan pembahasan secara keseluruhan, perancangan Sistem Informasi Pengelolaan Badan Amil Zakat Nasional Kabupaten Bogor Berbasis Web maka dapat ditarik kesimpulan, sebagai berikut:

a. Dengan membuat sistem informasi pembayaran zakat secara online dapat menghemat waktu dan tidak mengganggu aktifitas kerja karna pembayaran bisa dilakukan dimana saja.

b. Membantu memberikan informasi program atau kegiatan BAZNAS Kabupaten Bogor terhadap masyarakat luas dengan mengakses website secara online dengan mudah.

c. Dapat melihat informasi laporan pemasukan zakat yang selalu update sehingga bisa di lihat kapan saja melalui website BAZNAS Kabupaten Bogor.

\section{REFERENSI}

[1] A. P. Dwipratama, Sistem Infromasi Manajemen Zakat, Infaq dan Sedekah Pada Badan Amil Zakat Nasional. 2011.

[2] A. Mukhlis and S. Beik, "Analisis Faktor-faktor yang Memengaruhi Tingkat Kepatuhan Membayar Zakat: Studi Kasus Kabupaten Bogor Analysis of Factors Affecting Compliance Level of Paying Zakat : A Case Study in Bogor Regency," vol. I, no. 1, pp. 83-106, 2013.

[3] R. A. dan M. S. Sukamto, Rekayasa Perangkat Lunak Terstruktur dan berorientasi objek. Informatika Bandung, 2014.

[4] P. P. Widodo and Herlawati, Menggunakan UML (Unified Modeling Language). Bandung: Informatika Bandung, 2011.

[5] S. Tjandra and C. Pickerling, "Aplikasi MetodeMetode Software Testing pada Configuration, Compatibility dan Usability Perangkat Lunak," 2015.

[6] U. Marzuki, Kiat Mudah Zakat. Bogor: Badan Amil Zakat Nasional Kabupaten Bogor, 2015.

[7] A. I. Gufroni, I. Wisandani, and H. Sukmawati, "Sistem Informasi Unit Pengumpul Zakat Terintegrasi (Studi Kasus : BAZNAS Kota Tasikmalaya)," Jnteti, vol. 3, no. 4, pp. 236-241, 2014.

[8] A. D. Indriyanti, "Perancangan Sistem Informasi Pengelolahan Zakat Personal Berbasis Web PERANCANGAN SISTEM INFORMASI PENGELOLAHAN ZAKAT PERSONAL BERBASIS WEB," Inov. J. Ilm. Inov. Teknol. Inf., vol. 2, no. 2, pp. 80-91, 2017.

[9] Anofrizen and L. I. Wati, "Siak," Jurna l Rakayasa Dan Manaj. Sist. Inf., vol. 2, no. 2, 2016. 